\title{
Tropical Forest Restoration within Galapagos National Park: Application of a State-transition Model
}

\author{
$\underline{\text { S.R. Wilkinson }}^{1}, \underline{\text { M. A. Naeth }}^{1}$, and $\underline{\text { F.K. A. Schmiegelow }}{ }^{1}$
}

\begin{abstract}
Current theory on non-equilibrium communities, thresholds of irreversibility, and ecological resilience suggests the goal of ecological restoration of degraded communities is not to achieve one target, but to reestablish the temporal and spatial diversity inherent in natural ecosystems. Few restoration models, however, address ecological and management issues across the vegetation mosaic of a landscape. Because of a lack of scientific knowledge and funds, restoration practitioners focus instead on site-specific prescriptions and reactive rather than proactive approaches to restoration; this approach often dooms restoration projects to failure. We applied a state-transition model as a decision-making tool to identify and achieve short- and long-term restoration goals for a tropical, moist, evergreen forest on the island of Santa Cruz, Galapagos. The model guided the process of identifying current and desirable forest states, as well as the natural and human disturbances and management actions that caused transitions between them. This process facilitated assessment of opportunities for ecosystem restoration, expansion of the definition of restoration success for the system, and realization that, although site- or species-specific prescriptions may be available, they cannot succeed until broader landscape restoration issues are identified and addressed. The model provides a decision-making framework to allocate resources effectively to maximize these opportunities across the landscape, and to achieve long-term restoration success. Other restoration models have been limited by lack of scientific knowledge of the system. State-transition models for restoration incorporate current knowledge and funds, are adaptive, and can provide direction for restoration research and conservation management in other degraded systems.
\end{abstract}

Key Words: ecological resilience; ecosystem management; invasive species; restoration model

\section{INTRODUCTION}

A paradigm shift occurred in restoration ecology with the recognition of dynamic, non-equilibrium ecosystems and a reduced focus on single paths to restoration (Pickett and Parker 1994). Diverse factors that alter the natural fluctuations of communities, causing a change in ecosystem composition, structure, or processes, are now recognized. Both natural and anthropogenic disturbances can result in communities that sustain themselves, but do not resemble the predisturbance community (George et al. 1992, Allen-Diaz and Bartolome 1998). Thus, the goal of restoration of degraded communities becomes the reestablishment of the temporal and spatial diversity inherent in natural ecosystems (Parker 1997).
State-transition models (Westoby et al. 1989, Laylock 1991) are based on the assumption that alternative states exist in communities, and communities are rarely in equilibrium. The concept of ecosystem resilience embraces multiple system states. A given state persists until events or processes cause changes in the types or groups of species, and the system is forced to reorganize (Holling 1973, Walker 1995, Peterson et al. 1998). Management based on ecological resilience emphasizes the need to view events or disturbances in a regional rather than a local context, and to maintain spatial heterogeneity (Holling 1973). In state-transition models, transitions can occur from one state to another in the presence of natural or anthropogenic events and processes. Across a given 
landscape, a mosaic of states or levels of disturbance exist, with the number of possible states dependent upon the community or landscape.

State-transition models have been criticized for underestimating the number of potential states because of insufficient scientific knowledge, and for defining states based on management criteria (Rodrigues Iglesias and Kothmann 1997). Statetransition models are based on species composition and abundance, and assume these conspicuous ecosystem components are a direct result of a specific set of soil, geomorphic, and climatic attributes. Although not truly stable, states maintain the species composition and structure that define them for a period of time relevant to management regimes.

State-transition models can guide decision-making processes by identifying possible outcomes of each current state and the conditions required for transition between states. Disturbed plant communities may not revert to predisturbance conditions if certain ecological thresholds have been exceeded (Lugo 1988, Aronson et al. 1993). These thresholds of irreversibility mark the point where a system will not naturally return to its previous state, and human assistance through ecological restoration is required. Laylock (1991) suggests the use of state-transition models can increase the feasibility of management programs and reduce false expectations. Undesirable states can be identified, as well as the activities that facilitate transition to these states, and a proactive approach taken to prevent their occurrence (Westoby et al. 1989, Whalley 1994).

Although state-transition models have been applied to grassland communities, most under grazing (e.g., Westoby et al. 1989, Laylock 1991, George et al. 1992, Jones 1992, Bertiller and Bisigato 1998), only a few studies have applied them to forest communities (e.g., Llorens 1995, Perry and Enright 2002), and even fewer to ecosystem restoration. Yates and Hobbs (1997) suggested the use of a statetransition model for restoration of temperate Australian woodlands impacted by land clearing and overgrazing, and encouraged further exploration of uses for restoration of other ecosystems. We have applied a state-transition model to native, moist evergreen forest in the Galapagos Islands, Ecuador, that is threatened primarily by invasive, alien plant species. The degraded Scalesia forest community demonstrates the use of such a model as a decision- making tool to identify and achieve short- and longterm restoration goals.

\section{SCALESIA FOREST COMMUNITY}

Scalesia forest is found on four islands within the Galapagos archipelago (Table 1). Although $97 \%$ of the land area of the Galapagos Islands is within the Galapagos National Park (GNP), on Santa Cruz and San Cristobal significant portions of the Scalesia forest zone are outside the park, and have been cleared for agriculture and grazing. Grazing by feral goats on the island of Santiago has resulted in the near extirpation of Scalesia forest. Remaining tracts of forest are fragmented by goat grazing and abandoned pasture, and encroached upon by invasive grasses, trees, and shrubs. Our statetransition model was developed for the Scalesia forest community on the island of Santa Cruz (Fig. 1). It may apply to other Scalesia communities in the Galapagos, although differences in species composition, soils, land use, and management may alter outcomes.

On Santa Cruz, the Scalesia forest is situated within the Humid Zone, and receives a mean annual precipitation of approximately $1845 \mathrm{~mm}$ (Itow 1992). Soils are up to $1 \mathrm{~m}$ deep, of basaltic origin, well weathered, and sandy loam in texture (Laurelle 1966). The forest is even aged, and dominated by the endemic evergreen tree, Scalesia pedunculata Hook fil. The Scalesia forest on the north side of Santa Cruz Island is the last remaining stand of any significance in Galapagos (Itow 1995). Shimizu (1997) explicitly called for a three-tiered approach to conserving the forest by maintaining natural conditions (preventing further invasion), eliminating introduced plants and animals, and restoring Scalesia forest in disturbed areas. The goal of restoration is to place disturbed communities on trajectories toward the species diversity, abundance, and structure of uninvaded forest, in a cost-effective manner. The Scalesia forest in undisturbed areas on the north side of Santa Cruz is assumed to represent the species diversity, composition, and structure present over the past 200 years. Direct human impacts on this community have been small and recent (within the past 50 years). 
Table 1. Estimates of the pre-settlement and current area of the Humid Zone on the four islands where Scalesia forest is present, Galapagos. The Humid Zone comprises Scalesia pedunculata forest and a fernsedge zone on the islands of Santa Cruz and San Cristobal

\begin{tabular}{lcc}
\hline \hline Island & Pre-Settlement $\left(\mathrm{km}^{2}\right)$ & Current $\left(\mathrm{km}^{2}\right)$ \\
\hline Santa Cruz & 118 & 28 \\
San Cristobal & 84 & 6 \\
Floreana & 31 & 23 \\
Santiago & 35 & $\leq 0.1$ \\
\hline
\end{tabular}

Source: Charles Darwin Research Station database, unpublished maps and data.

\section{MODEL DEVELOPMENT}

To define states $(\mathrm{S})$ and transitions $(\mathrm{T})$ within the model (Fig. 2), an understanding of the dynamic nature of the forest community, the causes behind the persistence and expansion of invasive species, and the potential effects of existing land use and future management on the forest was necessary. Information was gained from the literature, discussion with researchers at the Charles Darwin Research Station (CDRS) and residents of Santa Cruz, and observations during invasive species management and forest restoration research conducted between 1997 and 2000.

\section{IDENTIFIED STATES}

\section{Native Scalesia Forest (S1 and S2)}

State $\mathrm{S} 1$ is Scalesia forest of high conservation value (Fig. 2). These forests have experienced little or no access by humans, and support the full suite of native plant and animal species representative of that forest. On the south side of the island, few such areas exist, but there is remnant forest on the north side.

Scalesia pedunculata comprises $60-100 \%$ of the forest canopy. Plant species diversity is lower, and forest structure simpler than other moist tropical forests (Hamann 1979, Itow 1995). Subcanopy species include Psidium galapageium Hook f. var. galapagieum, Chiococca alba (L.) Hitchc., Zanthoxylum fagara (L.) Sarg., Tournefortia rufosericea Hook f., and Psychotria rufipes Hook f. The understory is dominated by ferns (including Ctenitis pleiosoros (Hook f.) Morton, Dennestadia globulifera (Poir.) Hieron., Pteridium aquilinum (L.) Kuhn var. arachnoideum (Kaulf.) Herter, and Blechnum occidentalis Sodiro), herbaceous species (including Borreria laevis (Lam.) Griseb, Blechum browneii Juss. F., Ageratum conyzoides L., and Commelina diffusa Burdm. F.), and grasses (including Ichnanthus nemerosus (Sw.) Doell and Paspalum conjugatum Berguis) (Wilkinson 2002).

In the years following El Niño events, the Scalesia forest undergoes stand-level dieback (S2) (Hamann 1979, Lawesson 1988, Itow 1995, Shimizu 1997). Although not every El Niño triggers such an event, the extreme ones - every 10-15 years - may. The strong winds and rains may weaken the tall, spindly, shallow-rooted Scalesia trees, and in the following drought years, trees die back (Lawesson 1988). Once a few trees fall to the ground, the disturbance generally causes other trees to fall, through direct collision and increased wind exposure. Synchronous Scalesia regeneration only occurs once the canopy is opened.

\section{Native Forest with Alien Species (S3 and S4)}

State $\mathrm{S} 3$ is Scalesia forest with the full suite of native species and alien plant species present in low to moderate abundance. Alien plant species are those that have not arrived naturally in the islands by wind, water, and birds, but were transported either accidentally or intentionally by humans and their activities. These species are mainly herbaceous, with a few shrubs of the Asteraceae and Solanaceae 
Fig. 1. Vegetation zones on the island of Santa Cruz, Galapagos. The Scalesia forest and fern-sedge zones collectively comprise the Humid Zone. Inset figure of Santa Cruz (in black) within the context of the main Galapagos islands. Adapted from Itow (1992)

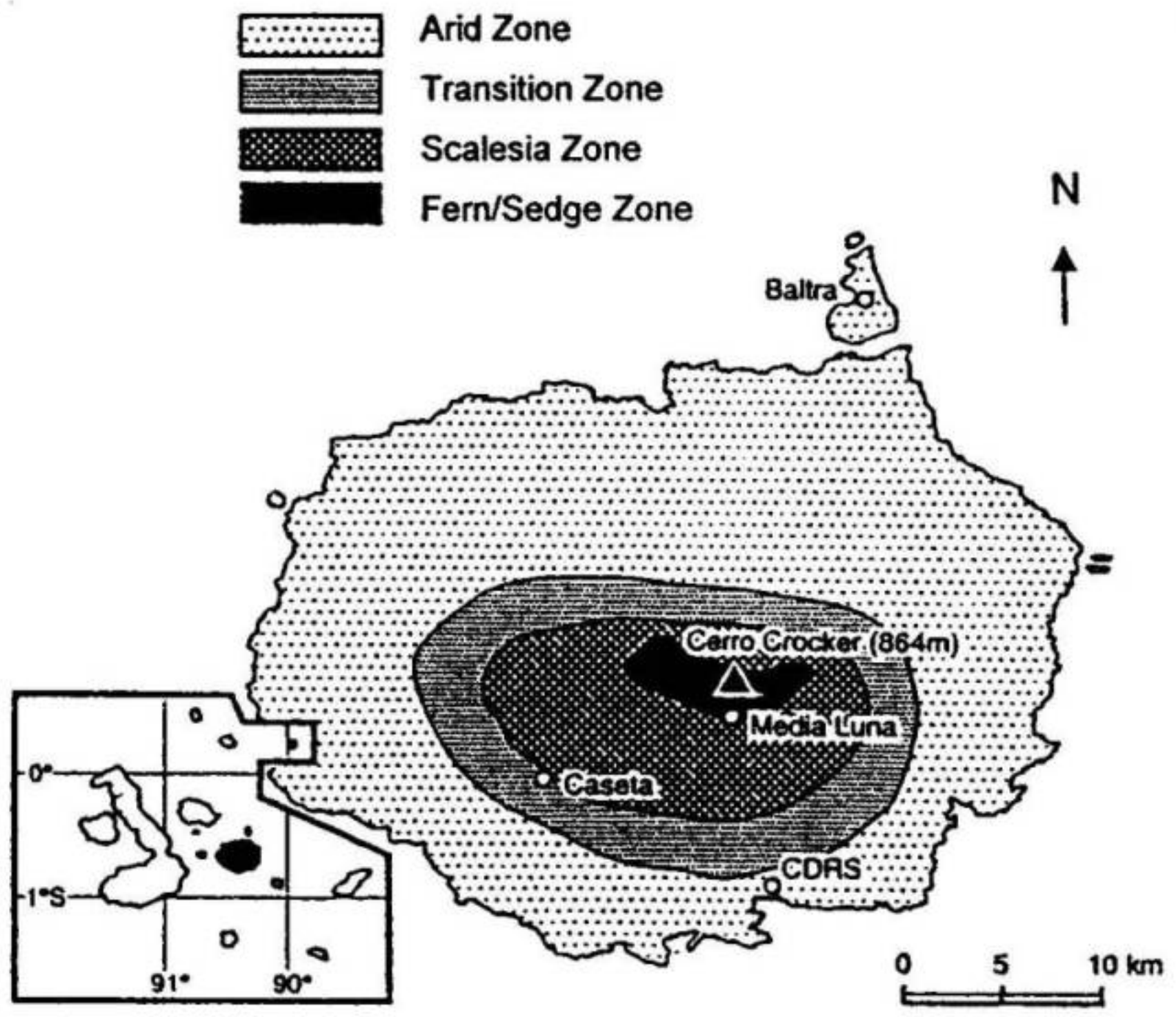

families. Forest in this state is common and considered of moderate to high conservation value. Such Scalesia stands will also experience natural dieback, resulting in S4, Scalesia forest with numerous small to large canopy gaps and alien

species present. 
Fig. 2. State-transition model for restoration of Scalesia pedunculata forest within Galapagos National Park. Lines and arrows indicate transitions (T) between states (S); dotted lines indicate those that are obstacles to restoration; and solid lines those that provide opportunities for restoration. Key to transitions: T1-forest canopy gaps; T2-limited resources for management; T3-direct clearing of forest; T4-unrestricted access to forest; T5-natural regeneration; T6-special protection status for Scalesia forest; T7-management of alien plants and animals; T8-native propagule addition.

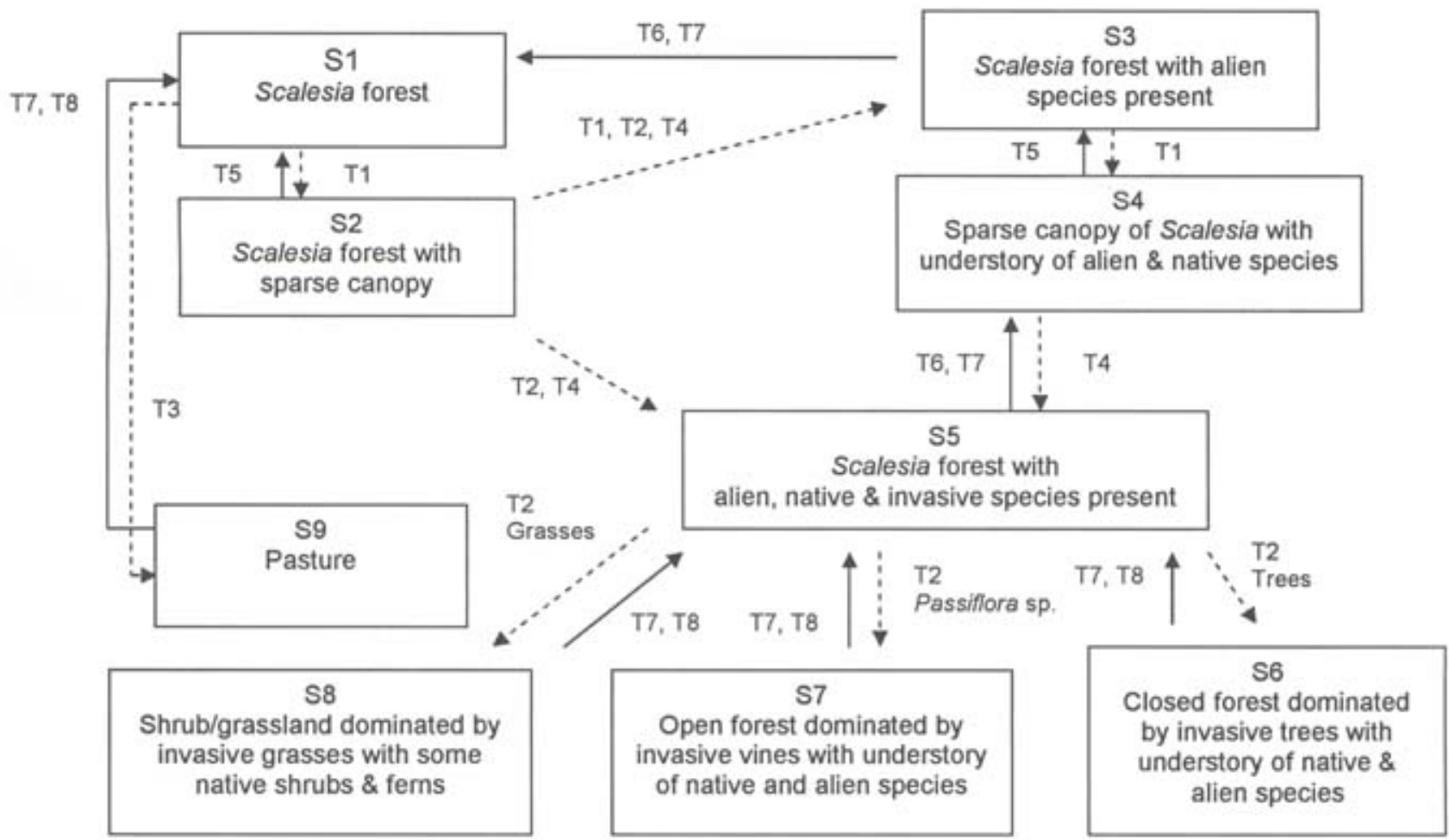

\section{Native Forest with Alien and Potentially Invasive Species (S5)}

State S5 forest has a moderate to high presence of alien species, some of which are potentially invasive based on experiences elsewhere (Hamann 1984, Tye 2001), but have not had known impacts within Galapagos. Invasive plant species are a subset of alien species; rather than persisting in harmony with the native community, they alter the community's composition, structure, and potentially, function (Cronk and Fuller 2001). For example, Jaeger
(1999) found Cinchona pubescens Vahl. (red quinine) invasion resulted in a 50\% decrease in cover of the endemic shrub, and community dominant, Miconia robinsoniana Cogn. in the highlands of Santa Cruz. Mauchamp et al. (1998) reported the invasion of Lantana camara L. as the cause of extinction of an endemic Galapagos plant. In this state, most native species are present and Scalesia still dominates the canopy. Given the right conditions, opportunistic characteristics that allow invasive species to persist and spread ensure they are more effective competitors than native species 
for limited resources, potentially resulting in local extirpation of native species (Hobbs and Humphries 1995). This state differs from the next three states, S6 to S8, in that no one invasive species or group dominates the community.

\section{Closed Forest Dominated by Invasive Trees (S6)}

Once introduced, invasive tree species such as $C$. pubescens, Psidium guajava L. (guava), and Cestrum auriculatum L'Her. (sauco) will eventually dominate the forest (S6). Researchers have noted the dominance and persistence of guava, quinine, and sauco in native forest for more than 25 years in the islands, with a much reduced understory richness. These species persist through prolific seed production and root and shoot suckers; traits that significantly reduce the effectiveness of control measures. Some native understory species may survive; however, Scalesia will be locally extirpated because its seedlings are shade intolerant (Shimizu 1997). Scalesia tree canopies do not overlap, resulting in light levels of approximately $7.6 \%$ (Shimizu 1997); invasive trees, however, create denser canopies. Changes in understory composition and abundance can also result in changes in soil properties that prevent native species from reestablishing (Ley and D'Antonio 1998, Holl et al. 2000).

\section{Open Forest Dominated by Invasive Vines (S7)}

Four Passiflora vine species are known in Galapagos, and two can smother Scalesia trees and other native vegetation (Wilkinson, pers. obs.). Passiflora is a well known invasive genera in tropical regions (Binggeli et al. 1998). Once the canopy trees are killed by the vines, regeneration will not occur and only shade-tolerant native and alien understory species will remain (S7).

\section{Shrub-Grassland Dominated by Invasive Grasses (S8)}

Once introduced, invasive pasture grasses, such as Pennisetum purpureum Schum. (elephant grass) and Melinis minutiflora Beauv. (molasses grass), will dominate the community, changing it from forest to a shrub-grassland (S8). Mat-forming grasses prevent regeneration of Scalesia and other shade- intolerant species. Some native shrub and fern species can survive for a period of time with these grasses but alien and other invasive species will establish as conditions become inappropriate for native species.

\section{Grazed and Abandoned Pastures (S9)}

Land was cleared within the Scalesia forest on the north side of the island by local residents in the 1970s and forages were planted. Many pastures were only lightly grazed for 1 to 2 years before National Park officials removed the cattle. In agricultural areas adjacent to the National Park, grazing may still occur. Remaining abandoned or grazed pastures vary in size from 0.5 to 10 hectares. Under grazing, pasture will be composed of opportunistic native and alien species, with a high proportion of bare ground (S9).

\section{Desired States in a Restoration Context}

Desired states can be defined based on aesthetic, scientific, and socioeconomic criteria. Generally, areas of high conservation value and low disturbance are given priority for restoration (Hobbs and Humphries 1995, van Haveren et al. 1997). Within the Scalesia forest, areas of high conservation value would include those with high occurrence of endemic and rare species, overall high species diversity and absence of alien species. The presence of alien and invasive species is the direct result of forest community disturbance. An array of disturbance factors initially contributed to their introduction, and result in their spread to new areas. They are the most conspicuous measure of disturbance in the Scalesia forest; the greater the richness and abundance of alien and invasive species, the greater (intensity or frequency) the disturbance.

A gradient in community degradation can be formed based on these criteria, with native Scalesia forest, S1 and S2, becoming the most desired states, and monocultures of invasive alien species, S6 to S9, the most degraded and least desired states. Restoration efforts aim to place degraded communities on a trajectory toward S1. Intermediate states would have varying composition and abundance of endemic, native, and alien species. Although S1 and S2 are most desirable, a satisfactory short-term goal could be between $\mathrm{S} 1$ 
and S4, as ecological thresholds of irreversibility have not been reached, and natural regeneration and assisted natural recovery are still possible.

\section{STATE-TRANSITIONS}

States remain relatively stable for long periods of time and only change because of natural or human disturbance. Direct transitions or linkages do not occur between all states; some have one, and others three or more. Transitions that move away from the desired S1 state toward more highly degraded states have been identified as obstacles to restoration, whereas transitions that move from degraded to less degraded states are identified as restoration opportunities. Obstacles are not impenetrable barriers; our intent by using this term is to emphasize that these factors must be recognized, and extra effort directed to mitigate their negative effects on successful restoration. Opportunities must also be recognized and extra effort directed to facilitate them. Each forest stand or patch may have specific forces that cause it to move to another state, and it is not our intention to identify them in detail. Our intent is to determine the main processes that cause transitions toward or away from desired restoration states so management decisions can be made. Four key obstacles and four key opportunities have been identified.

\section{Obstacles to Restoration}

\section{Forest canopy gaps (T1)}

Located at the crossways of the Humboldt (Peru) and Gulf currents, the islands experience regular El Niño events, with minor events every 3 to 4 years and major events every 15 to 20 years (Hamann 1985, Lawesson 1988). During an El Niño, ocean temperatures dramatically increase, leading to high precipitation and cool air temperatures. Years following an El Niño are often marked by drought. Many invasive species flourish under extreme wet and dry conditions, and range expansion within the Scalesia forest has been noted during drought years following the 1982-1983 (Hamann 1985) and 1999 (Wilkinson, pers. obs.) El Niños. Although native species are adapted to these events, and some-such as Scalesia-are even dependent on them for regeneration, the major events lead to openings in the forest canopy that provide opportunities for the spread of alien and invasive species already present.
This dilutes the native species pool, and reduces the conservation value of the forest over a greater region.

\section{Limited resources (T2)}

Equipment, supplies, labor and knowledge of appropriate management actions are required for successful restoration of plant communities. Financial resources for conservation are often limited in developing nations, and because of the isolated location of Galapagos, a wide array of equipment and materials are not readily available. As of 1999, 471 alien species were known in Galapagos (Tye 2001). Although many alien species only inhabit their site of introduction (e.g., agricultural field or garden), some escape and persist without human assistance in natural or seminatural areas (Cronk and Fuller 2001). On Santa Cruz, a dozen or so of these species now comprise a small but consistent component of native communities (Tye 2001). A few of these species are ubiquitous pantropical weeds, and it is difficult to determine if they were introduced naturally or by human activity. Although they are not a component of the native community, and therefore, not a longterm restoration goal, they may be considered acceptable in the short term, as invasive species should be of higher priority given limited resources.

Approximately 32 of the alien species in Galapagos are invasive (Tye 2001). Open access to the forest community and presence of invasive species in surrounding forest increase the likelihood that seed will be introduced onto restoration sites by natural or anthropogenic agents (Cronk and Fuller 2001). Invasive species may remain in low abundance for a period of time, but eventually seed banks will accumulate, causing state-transition. The time lag between introduction, exponential spread, and dominance can range from tens to hundreds of years (Lonsdale 1993, Hobbs and Humphries 1995), with longer time lag in trees (Kowarik 1995). The type (s) of species present will determine the outcome of this transition. However, when invasive plants are scattered, and as the native plant community reestablishes, the risk of off-target effects from herbicide use increases. Consequently, management actions are often not undertaken when populations are small, facilitating seed bank accumulation (Cronk and Fuller 2001).

Proven methods and adequate resources are required to prevent the spread of these species and 
further degradation of native forest. Although effective control methods are known for some species, they are not known for all present in the Scalesia forest. Even when methods are known, the required resources are not always available to successfully implement them, or their use may cause greater damage to the natural environment. For example, applying herbicide to the cut stems of Passiflora vines has been successful (e.g., Pacific Island Ecosystems at Risk (PIER) 2003), however, missed stems readily resprout and the number of workers required to effectively cover the extent of Passiflora distribution is formidable. Allocation of insufficient resources, a result of ad hoc approaches to controlling invasive species, frequently results in reduced momentum as goals are rarely achieved. In another example, picloram-based herbicides have effectively controlled $C$. pubescens in the highlands (Buggenheim et al. 2004). This chemical, however, is persistent in the soil (Tu et al. 2001) and its effects on native plant establishment are not known. Commonly used herbicides in North America are also often not available in Ecuador. Triclopyr-based products have successfully controlled invasive species elsewhere, and control trials in Galapagos during the late 1990s (Gardener et al. 1999) found this chemical was effective on P. guajava. However, more than research quantities were not available in Ecuador until recently.

\section{Forest clearing (T3)}

Land clearing for agriculture or plantations results in communities devoid of native vegetation and degraded soil conditions. Although unlikely to occur at a large scale, Scalesia forest bordering agricultural and park zones has been and may continue to be cleared. Soils of the Scalesia forest vegetation zone are deeper and more fertile than in other parts of the islands, and with high precipitation provide ideal conditions for agriculture. In the future, land in the National Park border region could be cleared for tourism development as this is a growing industry in the islands.

\section{Unrestricted park access (T4)}

Current access management within the GNP facilitates new introductions and local forest disturbance. Although the GNP has restricted access to a number of islands, access to National Park areas on the island of Santa Cruz is not strictly controlled. Official trails do not exist, except to Cerro Crocker, but numerous unofficial trails occur throughout the
Scalesia forest zone. Local residents access this region for harvesting fruit, hunting, recreation, and animal grazing. Conservation management and research activities, and tourism also result in increased access. Impacts of access include trail creation, trail widening, soil disturbance, cutting of vegetation, species introduction, and dispersal of introduced seed to new areas by means of clothing and footwear.

Unrestricted forest access by domesticated or feral animals also alters the plant community. Free-range cattle grazing has been tolerated within the National Park, particularly during recent drought years. Horses are commonly used to access the National Park because of its distance from settlement and lack of roads. Although feral animals, including goats and pigs, are thought to have been eradicated on the island, a few likely remain. Seed of undesirable plant species is spread to undisturbed forest regions in animal feces and on their fur and feet. Their grazing activities disturb the soil, particularly under wet conditions, creating ideal sites for further alien plant species establishment.

\section{Opportunities for Restoration}

\section{Natural regeneration (T5)}

Many species native to the Scalesia forest have traits of ideal colonizers of disturbed sites (Porter 1983). Flora on other oceanic islands, where dispersal barriers limit arrival of species and environments are harsh for establishment, require species with aggressive growth strategies (Vitousek et al. 1995) such as rapid growth and sexual maturity, high seed production, and tolerance of disturbance. Scalesia, the dominant tree, is part of the Asteraceae family, and is more similar to a herbaceous weed than a typical, slow-growing, tropical forest tree. As colonizers of the islands, many native species have seed that is small and dispersed by wind or water, and therefore, adapted to long-distance dispersal (Porter 1983). Consequently, these native species may be able to reestablish much quicker than predicted based on other forest restoration efforts (e.g., Lugo 1988, Aide et al. 2000). However, competitive abilities of native species, particularly those endemic to the islands, may be much reduced as they have developed in isolation, with little need for strategies to compete for resources (Simberloff 1995). 
Reliance on the relict seed bank and dispersal from neighboring areas reduces short-term costs, accelerates restoration, reduces invasion potential, and increases the genetic diversity and resilience of the community (Lugo 1988, Linhart 1995). The greater the abundance of native species or patches of remnant vegetation (S3 to S5), the greater the feasibility and speed of natural recovery. Native shrubs (e.g., Tournefortia rufo-sericea and Psychotria rufipes) and ferns resist displacement in early stages of invasion due to vegetative reproduction. Once invasive species are suppressed, native species may readily spread from adjacent forest onto restoration sites by seed or vegetative propagules (Hamann 1984). Within the park zone on Santa Cruz, a large portion of Scalesia forest exists in relatively pristine states (S3 and S4). The smaller the area or patch of infestation, the greater the potential for natural recovery. Dispersal from adjacent areas may be more important for many native species as the soil seed bank of the native forest and abandoned pastures is dominated by alien species, with only a few natives present (Wilkinson 2002).

\section{Special protection status (T6)}

Management of the Scalesia forest zone as a sensitive protected area could help prevent and reverse undesirable changes in the plant community. Incorporation within GNP invokes clear regulations on most of the islands, but not on the highly populated Santa Cruz. The isolation of the Scalesia forest on the north side of Santa Cruz from main settlements on the south side has greatly reduced access compared with other regions of the Humid Zone. However, management actionsincluding education, policy development, and enforcement - that recognize this forest as highly vulnerable to disturbance could enhance forest conservation.

Access to protected areas is repeatedly cited as a factor in the expansion of alien species (Macdonald 1990, Cronk and Fuller 2001, Reichard 1997). Humans are a component of the Galapagos ecosystem, and therefore, cannot be wholly removed. However, human impacts can be minimized through education and community involvement in restoration. The success of access management hinges on consistent policy and enforcement. As the abundance of alien fruit trees, vines, and animals is reduced, frequency of access for these purposes will also decrease. Even if activities within the park zone do not cease, a reduction in activity will result in fewer introductions and dispersal of seed of alien species. The number of aliens has increased significantly in the past two decades in conjunction with the island's population; the greater the number of alien species, the greater the risk that one or more are invaders (Mauchamp 1997).

\section{Management of invasive plant species (T7)}

Few protected areas are isolated from outside forces, and the introduction and establishment of nonnative plant and animal species is a constant problem. Scalesia forest in states S3 and S4 provides the smallest cost-benefit ratio for restoration. Not only are many native species resilient to disturbance and sources of propagules available, but the low number of alien and invasive species significantly increases the chance of successful management. Lack of funds for intensive large-scale control programs is a common reason for inaction. Alien species that do not currently pose a threat to intact native plant communities, but are potential invaders based on experiences elsewhere, such as Persea americana Mill. (avocado) and Citrus spp., should be proactively removed to reduce future effort and expense (Hamann 1984). Pueraria phaseoloides (Roxb.) Benth. (kudzu), a notorious invader in the United States, was identified on a farm in the highlands and eliminated with successive herbicide applications before it became a problem on the island. Invasive species lists are widely distributed by a number of international organizations devoted to the understanding and management of these species. Success rates will be high, increasing management program momentum.

Forest in states S5 to S9 will first require removal of the dense cover of invasive species before natural recovery or assisted natural recovery can be considered. Integrated approaches to management of invasive plant species provide the most effective control, particularly when a suite of species with differing strategies exists (Hobbs and Humphries 1995, Randall 1996). Research in Galapagos and elsewhere has resulted in proven methods for the control of a number of invasive species in the Scalesia forest. Manual, chemical, and cultural methods have been considered for many species on the island, with focus on selective herbicide use (Wilkinson and Tye 1998, Soria et al. 2002). For example, Psidium cattleianum Sabine is a serious problem in Hawaii, however, much research and 
years of field experience indicate it can be controlled. Although it is a different species, the biology is similar to $P$. guajava, an invader in Galapagos, and thus it is highly likely that the same methods would result in similar levels of control. Rubus niveus has expanded exponentially on Santa Cruz since its introduction in 1983 (Mauchamp 1997). A control program has been successfully implemented in the agricultural zone on Santa Cruz, thereby reducing seed sources for adjacent Scalesia forest. Initiation of some form of invasive species management, whether the actions contain or eradicate a population, will direct a degraded site toward higher conservation value forest.

\section{Propagule addition (T8)}

Beyond S5, natural recovery may not achieve desired restoration goals as the composition of the relict seed bank becomes dominated by pantropical weeds or invasive species. Key species are missing from the soil seed bank of native forest (Wilkinson 2002), as found in studies of tropical forests elsewhere (Dalling et al. 1998, Baskin and Baskin 2001). Supplementary seeding of Scalesia and other fast-growing native species would be required, particularly when remnant vegetation is absent. Initial studies (e.g., Estupiñan 1987, Wilkinson 2002) on the potential for establishment of native species from seed indicate woody species can be hand collected, and herbaceous species will establish from the soil seed bank of non-invaded forest. Propagule addition, even if forest remnants exist, increases species diversity and rate of forest recovery, and therefore, ecosystem resilience.

In the tropics, plantations of native and non-native tree species have been found to catalyze succession on highly degraded lands, increasing native understory species richness, abundance, and diversity compared with sites left to natural recovery (Parotta et al. 1997). Tree species that rapidly establish and have high growth rates can ameliorate understory properties, including microclimate, soil moisture and temperature, litter and organic matter development, and nutrient cycling. Monocultures and mixed species plantings have successfully accelerated restoration (e.g., Rhoades et al. 1998, Leopold et al. 2001, Sayer et al. 2004). Non-native species are commonly planted for local economic benefit or where resources are not available to research establishment requirements for native species. Initial focus on establishment of Scalesia is desirable, as it is considered a driver species in the forest. Driver species have a strong ecological function and significantly structure the community in which they exist (Walker 1992). Scalesia forms a monoculture in the forest canopy, and is hypothesized to have a significant effect on composition and structure of the subcanopy and understory vegetation and soil properties. Nonnative species are not acceptable within the Galapagos Islands because of the risk of invasiveness. Although initial planting efforts would be resource intensive, particularly with limited site access, the restoration benefits and longterm reduction in management could be substantial.

Establishment of trees on which birds can perch may also facilitate the addition of bird-dispersed seeds (Holl 1998). This will be of particular importance in forest of states S7 to S9, where birds may not traverse the large, open areas. Birds and wildlife not only disperse seed but may break seed dormancy in native species. Efforts have been undertaken to reestablish Opuntia species by passing their seed through the gut of giant tortoises (Geochelone elephantopus). Tournefortia rufo-sericea seed germination was low when direct seeded (Wilkinson 2002), but its berries may need to pass through the gut of bird species to improve germination. Experimenting with simple preseeding treatments such as seed scarification, which simulates this process, may significantly increase its germination and that of other bird-dispersed species. However, Scalesia tree plantings may be sufficient to attract bird dispersers and catalyze forest succession.

\section{APPLICATION OF STATE-TRANSITION MODEL AS A DECISION-MAKING TOOL}

The greatest obstacle to restoration success in many protected areas may not be lack of knowledge or funds, but lack of a cohesive framework to facilitate decision making, given current knowledge and funds. A state-transition model can be used to enact proactive management by maximizing restoration opportunities and minimizing obstacles.

A key outcome of our state-transition model is that it allows for expansion of the definition of restoration success. Such an expanded definition increases opportunities for successful outcomes from ecological restoration efforts given current input levels; the perception of "hands are tied" in response to degraded communities is defeated. 
Forest in states S3 and S4 is sustainable in the absence of disturbance caused by unrestricted human and animal access. Although alien species are not preferred, the restoration objectives of maintaining and enhancing native and endemic species richness and abundance can still be achieved. Many alien species pose little threat, persisting in low abundance with the native plants. In some situations, they may improve site conditions for native species (Kamo et al. 2002, Lugo 2004a). Lugo (2004b) suggests that these alien species may need to be accepted as a common component of "new forests" of the human-development landscape. Even within S1 and S2 forest, species composition and dominance are variable over space and time (e.g., wet vs. dry season). Patches without Scalesia canopy are desirable for regeneration of the species and growth of understory species. Plant community restoration objectives need to allow for this variability and accept alien species when in low abundances and when removal may only disrupt the system in favor of invaders.

A map of current states is required to visualize the vegetation mosaic of the forest and management landscape. There should be no a priori focus on a particular state of forest, and all patches should be clearly delineated. The number of states within the model may be adapted following field surveys. Once classified and mapped, the frequency and area of each of the states can be determined, and the status of the overall forest community assessed. The model and resulting distribution map are the basis of management solutions.

The conventional approach to mapping exercises such as this is to look at the various states of forest and create prescriptions to manage dominant invasive species and push them toward S1 and S2 forest. Individual species of concern may be identified, and known methods to control them researched. The state-transition model emphasizes that, even if species specific management or restoration knowledge was available, community restoration cannot be achieved without first addressing landscape-level obstacles of access and introduction of alien species from outside seed sources. States S1 to S4 are directly threatened by continued access by humans and animals. No amount of research would reduce this threat, although low levels of resources could implement an access policy. Beyond state S5, access is no longer the primary determinant of restoration success, as establishment and dominance of identified invasive plant groups is inevitable. Fewer resources are required to remove invasive and potentially invasive species once seed dispersal vectors and localized disturbance are removed from the system; natural recovery will then occur if ecological thresholds have not been crossed.

A restoration focus on highly degraded sites occurs because they are easier to identify, harder for society to ignore, and results, at least in the short term, are more noticeable. However, long-term success is not easily obtained, and a history of repeated failure can lead to inaction. In the past, the focus has been on control of undesirable plants; however, if this is coupled with establishment of desirable species, the rate of restoration success will increase (Berger 1993). The model emphasizes the need for this approach by highlighting where a focus on one group of species (desirable vs. undesirable) is appropriate, and where a more balanced approach is required. Forest in states S8 and S9 has few immediate opportunities for natural recovery even if management inputs to control invasive species are available. Whereas other studies in tropical regions have found native species to invade abandoned pastures naturally (Aide et al. 2000, Lugo 2004b), more than 30 years following abandonment, no native species were observed in the $P$. purpureum pastures of the Scalesia forest, and natural recovery is not likely to occur in forest of this state. Although some non-native species have improved site conditions for establishment of native species, dominant species in the Scalesia forest, such as $P$. purpureum and $P$. guajava, have not (Rhoades et al. 1998, Chapman and Chapman 1999). States S6 and S7 will benefit from removal of the dominating invader group, but establishment of native species to fill these empty gaps or niches in the plant community will be necessary to prevent reinvasion and put the forest on a trajectory toward desirable states. Removal of invasive species in S5 forest can facilitate community restoration. Assisted natural recovery, however, accelerates this process and reduces opportunities for reinvasion.

By preventing forest from becoming more highly degraded (States S6 to S9), resources can be conserved and objectives more easily achieved. Because of the extent of the infestation at state S7, selective control methods are costly and nonselective methods cannot avoid damaging the native species that still remain. Rapid establishment of native species, which fill the gap of those species removed (e.g., canopy, subcanopy or understory), 
is desirable. A portion of the species pool may still remain in the soil seed bank or be dispersed from adjacent areas. Disturbed sites are more common in national parks around the world, and seed collection programs have been initiated to preserve the genetic diversity of the parks. As many native species have traits that allow them to readily establish, it is reasonable to assume that collection and sowing of seed from a variety of species will increase the rate of vegetation establishment to some degree, and certainly be an improvement over natural recovery. Wet tropical forest restoration research in other regions recommended mixed plantings to increase biodiversity, stability, and complexity (Chapman and Chapman 1999, Leopold et al. 2001). The greater the community degradation, the greater the number of species or species groups that will need to be reintroduced. Preliminary research indicates ferns persist in the seed bank, and given sufficient moisture and shade will reestablish. Trees and herbaceous species will require the most assistance to reestablish.

A complementary strategy is to focus restoration efforts on core conservation areas. Core areas within the context of this restoration model are those of high conservation value (S1 and S2). Forest of lesser conservation value, ranging from $\mathrm{S} 3$ to $\mathrm{S} 9$, surrounds these core areas. Core areas could be expanded to include forest in states S3 and S4, particularly if this is a significant portion of the vegetation mosaic. Connection of core areas of high-conservation forest, through forest restoration efforts, will result in larger patches and reduced amount of edge, increasing community resistance to further invasion (Janzen 1983). Core areas will grow over time if obstacles to restoration are addressed and opportunities exploited. These core areas then become valuable sources of seed for restoration of degraded forest. Although cyclic stand dieback and forest canopy gaps will occur in perpetuity, reducing the resilience of core areas, this cycle can also provide opportunities for proactive management. Forest gaps are ideal sites for the observation and study of native species' regeneration strategies. This will assist in the development of a list of species with potential for rapid establishment in the Scalesia forest. Areas highly susceptible to windthrow can be identified, adjacent sources of invasive species recorded, and appropriate management taken before or during these events. The impact of Scalesia stand dieback would be reduced in larger core areas. In small areas, the loss of Scalesia canopy cover could result in significantly reduced ecological resilience and domination by invasive tree species; whereas in a larger patch, it is unlikely that all trees would experience synchronous dieback.

\section{Application to Other Communities}

Restoration of spatial and temporal heterogeneity leads to increased ecological resilience and restoration success. The Scalesia forest discussed in this paper shares many issues with other degraded plant communities in need of restoration. Moreover, the process of model development is universal; in every ecosystem, vegetation change in space and time is caused by natural and human events and actions. Ecological and socioeconomic factors specific to a given community must be incorporated into a model to produce useful outcomes. Regardless of the level of knowledge or resources, a vegetation mosaic will be produced for the community and an understanding of the links between states gained that can then be adapted as inputs change over time.

Ideally, management actions should move a plant community toward its desired states. Although siteand species-focused prescriptions provide management actions that cause transitions from highly degraded forest states to desired states, they cannot be effectively allocated until forest classification and mapping of all states has occurred. New obstacles to restoration may arise and new opportunities be identified through research, and trial and error in the field. The challenge in any system is to balance restoration opportunities, as overemphasis on any one at the expense of another may provide results in the short term, but will not lead to self-sustaining, resilient plant communities in the long term. In the short term, the relative importance of an opportunity will depend on the initial forest state and that of surrounding forest. As the vegetation mosaic of the community changes, priority areas for management may also change. System-level issues must continually be reevaluated and addressed before ecological restoration can be successfully implemented.

Responses to this article can be read online at: http://www.ecologyandsociety.org/vollo/iss 1/art28/responses/ 


\section{Acknowledgments:}

We thank the Canadian International Development Agency, the Charles Darwin Research Station, the Galapagos National Park Service, and the Department of Renewable Resources at the University of Alberta for support of this research. We also gratefully acknowledge Dr. Alan Tye for his contributions to the study and comments on this manuscript, as well as the comments of anonymous reviewers, which greatly improved the manuscript.

\section{LITERATURE CITED}

Aide, T. M., J. K. Zimmerman, J. B. Pascarella, L. Rivera, and H. Marcano-Vega. 2000. Forest regeneration in a chronosequence of tropical abandoned pastures: implications for restoration ecology. Restoration Ecology 8:328-338.

Allen-Diaz, B., and J. W. Bartolome. 1998. Sagebrush-grass vegetation dynamics: comparing classical and state-transition models. Ecological Applications 8:795-804.

Aronson, J., C. Floret, E. Le Floc'h, C. Ovalle, and R. Pontanier. 1993. Restoration and rehabilitation of degraded ecosystems in arid and semi-arid lands. II. Case studies in southern Tunisia, central Chile and northern Cameroon. Restoration Ecology 2:168-187.

Baskin, C. C., and J. M. Baskin. 2001. Seeds: ecology, biogeography and evolution of dormancy and germination. Academic Press, San Diego, California, USA.

Berger, J. J. 1993. Ecological restoration and nonindigenous plant species: a review. Restoration Ecology 1:74-82.

Bertiller, M. B., and A. Bisigato. 1998. Vegetation dynamics under grazing disturbance. The statetransition model for the Patagonian steppes. Ecología Austral 8:191-199.

Binggeli P., J. B. Hall, and J. R. Healey. 1998. An overview of invasive woody plants in the tropics. School of Agricultural and Forest Sciences
Publication Number 13, University of Wales, Bangor, UK. [Online.] URL:

http://www.bangor.ac.uk/ afs 101/iwpt/web1-99.pdf

Buggenheim, C. E., J. L. Renteria, M. Gardener, S. R. Wilkinson, M. Soria, P. Yanez, A. Tye, and R. Valle. 2004. The control of a highly invasive tree Cinchona pubescens in Galapagos. Weed Technology 18:1194-1202.

Chapman, C.A., and L. J. Chapman. 1999. Forest restoration in abandoned agricultural land: a case study from East Africa. Conservation Biology 13:1301-1311.

Cronk, Q. C. B., and J. L. Fuller. 2001. Plant invaders: the threat to natural ecosystems. Earthscan Publications. London, UK.

Dalling, J., S. Hubbell, and K. Silvera. 1998. Dispersal patterns and seed bank dynamics of pioneer trees in moist tropical forest. Ecology 79:564-578.

Estupiñan, I. N. 1987. Comportameinto inicial de Miconia robinsoniana y Scalesia pedunculata con fines de protección en San Cristobal, Galápagos. Charles Darwin Research Station. Puerto Ayora, Galapagos, Ecuador.

Gardener, M. R., A. Tye, and S. R. Wilkinson. 1999. Control of introduced plants in the Galapagos Islands. Pages 396-400 in A. C. Bishop, M. Boersma, and C. D. Barnes, editors. Proceedings from the Twelfth Australian Weeds Conference, 1719 September 1999. Hobart, Tasmania, Australia.

George, M. R., J. R. Brown, and W. J. Clawson. 1992. Applications of nonequilibrium ecology to management of Mediterranean grasslands. Journal of Range Management 45:436-440.

Hamann, O. 1979. Dynamics of a stand of Scalesia pedunculata, Santa Cruz Island, Galapagos. Botanical Journal of the Linnean Society 78:67-84

Hamann, O. 1984. Changes and threats to the vegetation. Pages 115-131 in R. Perry, editor. Key environments: Galapagos. Pergamon Press. Oxford, UK.

Hamann, O. 1985. The El Niño influence on the Galapagos vegetation. Pages 299-330 in G. 
Robinson and E. M. del Piño, editors. El Niño en las islas Galápagos: el evento de 1982-1983. Charles Darwin Foundation for the Galápagos Island. Quito, Ecuador.

Hobbs, R. J., and S. E. Humphries. 1995. An integrated approach to the ecology and management of plant invasions. Conservation Biology 9:761770 .

Holl, K. D. 1998. Do bird perching structures elevate seed rain and seedling establishment in abandoned tropical pasture? Restoration Ecology 6:227-313.

Holl, K. D., M. E. Loik, E. H. V. Lin, and I. A. Samuels. 2000. Tropical montane forest restoration in Costa Rica: overcoming barriers to dispersal and establishment. Restoration Ecology 8:339-349.

Holling, C. S. 1973. Resilience and stability of ecological systems. Annual Review of Ecology and Systematics 4:1-23.

Itow, S. 1992. Altitudinal change in plant endemism, species turnover and diversity on Isla Santa Cruz, the Galapagos Islands. Pacific Science 46:251-268.

Itow, S. 1995. Phytogeography and ecology of Scalesia (Compositae) endemic to the Galapagos Islands. Pacific Science 49:17-30.

Jäger, H. 1999. Impact of the introduced tree Cinchona pubescens Vahl. on the native flora of the highlands of Santa Cruz Island (Galapagos). Thesis, University of Oldenburg, Oldenburg, Germany.

Janzen, D. H. 1983. No park is an island: increase in interference from outside as park size decreases. Oikos 41:402-410.

Jones, R. M. 1992. Resting from grazing to reverse changes in sown pasture composition: application of the "state-and-transition" model. Tropical Grasslands 26:97-99.

Kamo, K., T. Vacharangkura, S. Tiyanon, C. Viriyabuncha, S. Nimpila, and B. Doangsrisen. 2002. Plant species diversity in tropical planted forests and implication for restoration of forest ecosystems in Sakaerat, northeastern Thailand. Japan Agriculture Research Quarterly 36:111-118.
Kowarik, I. 1995. Time lags in biological invasions with regard to the success and failure of alien species. Pages 15-38 in P. Pysek, K. Prach, M. Rejmánek, and P. M. Wade, editors. Plant invasions - general aspects and special problems. SPB Academic. Amsterdam, Netherlands.

Laurelle, L. 1966. Study of soil sequence of Indefatigable Island. Pages 87-92 in R. I. Bowman, editor. The Galapagos, proceedings of the symposia of the Galapagos international scientific project. University of California Press, Berkeley, California, USA.

Lawesson, J. 1988. Stand level dieback and regeneration of forests in the Galapagos Islands. Vegetatio 77:87-93.

Laylock, W. A. 1991. Stable states and thresholds of range condition on North American rangelands: a viewpoint. Journal of Range Management 44:427-433.

Leopold, A. C., R. Andrus, A. Finkeldey, and D. Knowles. 2001. Attempting restoration of wet tropical forests in Costa Rica. Forest Ecology and Management 142:243-249.

Ley, A., and C. D’Antonio. 1998. Exotic grass invasion alters potential rates of $\mathrm{N}$ fixation in Hawaiian woodlands. Oecologia 113:179-187.

Linhart, Y. B. 1995. Restoration, revegetation and the importance of genetic and evolutionary perspectives. Pages 271-287 in B. A. Roundy, E. D. McArthur, J. S. Haley and D. K. Mann, editors. Proceedings: wildland shrub and arid land restoration symposium. 19-21 October 1993. Las Vegas, Nevada. Gen. Tech. Rep. INT-GTR-315. U. S. Department of Agriculture, Forest Service, Intermountain Research Station, Ogden, Utah, USA.

Llorens, E. M. 1995. The state and transition model applied to the herbaceous layer of Argentina's calden forest. Journal of Range Management 48:442-447.

Lonsdale, W. M. 1993. Rates of spread of an invading species-Mimosa pigra in northern Australia. Journal of Ecology 81:513-521.

Lugo, A. 1988. The future of the forest: ecosystem 
rehabilitation in the tropics. Environment 30:17-45.

Lugo,A. 2004a. The outcome of alien tree invasions in Puerto Rico. Frontiers in Ecology and the Environment 2:265-273.

Lugo, A. 2004b. Emerging forests on abandoned land: Puerto Rico's new forests. Forest Ecology and Management 190:145-161.

Macdonald, I. A. W. 1990. Strategies for limiting the invasion of protected areas by introduced organisms. Monographs in Systematic Botany Missouri Botanical Gardens 32:189-199.

Mauchamp, A. 1997. Threats from alien plant species in the Galapagos Islands. Conservation Biology 11:260-263.

Mauchamp, A., I. Aldaz, E. Ortiz, and H. Valdebenito. 1998. Threatened species, a reevaluation of the status of eight endemic plants of the Galapagos. Biodiversity and Conservation 7:97-107.

Pacific Island Ecosystems at Risk (PIER). 2003. Passiflora tarminiana Coppens \& Barney. Institute of Pacific Islands Forestry. [Online.] URL:

http://www.hear.org/pier/species/passiflora tarminiana. $\underline{\mathrm{htm}}$.

Parrota, J. A., J. W. Turnbull, and N. Jones. 1997. Catalyzing native forest regeneration on degraded lands. Forest Ecology and Management 99:1-7.

Parker, V.T. 1997. The scale of successional models and restoration objectives. Restoration Ecology 5:3-1-306.

Perry, G. L. W., and N. J. Enright. 2002. Humans, fire and landscape pattern: understanding a maquisforest complex, Mont Do, New Caledonia, using a spatial "state-transition" model. Journal of Biogeography 29:1143-1158.

Peterson, G., C. R. Allen, and C. S. Holling. 1998. Ecological resilience, biodiversity, and scale. Ecosystems 1:6-18.

Pickett, S. T. A., and V. T. Parker. 1994. Avoiding the old pitfalls: opportunities in a new discipline. Restoration Ecology 2:75-79.

Porter, D. M. 1983. Vascular plants of the
Galapagos: origins and dispersal. Pages 33-96 in R. I. Bowman, M. Berson, and A. E. Leviton, editors. Patterns of evolution in Galapagos organisms. American Association for the Advancement of Science, San Francisco, California, USA.

Randall, J. M. 1996. Weed control for the preservation of biological diversity. Weed Technology 10:370-383.

Reichard, S. E. 1997. Prevention of invasive plant introductions on national and local levels. Pages 215-227 in J. O. Luken and J. W. Thieret, editors. Assessment and management of plant invasions. Springer, New York, New York, USA.

Rhoades, C. C., G. E. Eckert, and D. C. Coleman. 1998. Effect of pasture trees on soil nitrogen and organic matter: implications for tropical montane forest restoration. Restoration Ecology 6:262-270.

Rodrigues Iglesias, R. M., and M. M. Kothmann. 1997. Structure and causes of vegetation change in state-transition model applications. Journal of Range Management 50:399-408.

Sayer, J., U. Chokkalingam, and J. Poulsen. 2004. The restoration of forest biodiversity and ecological values. Forest Ecology and Management 201:3-11.

Shimizu, Y. 1997. Competitive relationship between tree species of Scalesia and introduced plants with reference to regeneration mechanisms of Scalesia forests in the Galapagos Islands. Institute for Applied Geography, Komazawa University, Tokyo, Japan. Regional Review 11:1131.

Simberloff, D. 1995. Why do introduced species appear to devastate islands more than mainland areas? Pacific Science 49:87-97.

Soria, M., U. Taylor, A. Tye, and S. R. Wilkinson. 2002. Manuel de identificatión y manejo de malezas en las isles Galápagos. Parque Nacional Galápagos y Fundación Charles Darwin. Puerto Ayora, Galapagos.

Tye, A. 2001. Invasive plant problems and requirements for weed risk assessment in the Galapagos Islands. Pages 153-175 in R. H. Groves, F. D. Panetta, and J. G. Virtue, editors. Weed risk assessment. CSIRO Publishing, Collingwood, Australia. 
Tu, M., C. Hurd, and J. M. Randall. 2001. Weed control methods handbook: tools and techniques for use in natural areas. The Nature Conservancy Wildland Invasive Species Team. April 2001. [Online.] URL:

http://tncweeds.ucdavis.edu/handbook.html.

van Haveren, B. P., J. E. Williams, M. L. Pattison, and J. R. Haugh. 1997. Restoring the ecological integrity of public lands. Journal of Soil and Water Conservation 52:226-231.

Vitousek, P. M., L. L. Loope, and H. Adsersen. 1995. Islands. Biological diversity and ecosystem function. Ecological Studies 115, Springer-Verlag Inc., Berlin, Germany.

Walker, B. 1992. Biological diversity and ecological redundancy. Conservation Biology 6:18-23.

Walker, B. 1995. Conserving biological diversity through ecosystem resilience. Conservation Biology 9:747-752.

Westoby, M., B. Walker, and I. Noy-Meir. 1989. Opportunistic management for rangelands not at equilibrium. Journal of Range Management 42:266-274.

Whalley, R. D. B. 1994. State and transition models for rangelands. 1. Successional theory and vegetation change. Tropical Grasslands 28:195205.

Wilkinson, S. R. 2002. Management of elephant grass and restoration of moist evergreen forest in abandoned pastures, Galapagos Islands, Ecuador. Thesis, University of Alberta, Edmonton, Alberta, Canada.

Wilkinson, S. R., and A. Tye. 1998. Introduced species in the Galapagos Islands: control efforts to date 1971-1998. Charles Darwin Research Station, Puerto Ayora, Galapagos, Ecuador.

Yates, C. J., and R. J. Hobbs. 1997. Woodland restoration in the western Australian wheatbelt: a conceptual framework using a state-transition model. Restoration Ecology 5:28-35. 